\title{
The Role of Assertiveness and Self-Assertion in Female High School Students' Emotional Self-Regulation
}

\author{
Bahman Allahyari ${ }^{1}$, Hossein Jenaabadi ${ }^{*}$ \\ ${ }^{1}$ Department of Psychology, Zahedan Branch, Islamic Azad University, Zahedan, Iran \\ ${ }^{2}$ Department of Education, University of Sistan and Baluchestan, Zahedan, Iran \\ Email: ${ }^{*}$ hjenaabadi@ped.usb.ac.ir
}

Received 11 April 2015; accepted 30 May 2015; published 19 August 2015

Copyright $@ 2015$ by authors and Scientific Research Publishing Inc.

This work is licensed under the Creative Commons Attribution International License (CC BY). http://creativecommons.org/licenses/by/4.0/

(c) (i) Open Access

\begin{abstract}
The current study aimed to investigate the role of assertiveness and self-assertion in emotional self-regulation of female students. The statistical population included all second period female high school students in Jalagh, in the academic year 2014-2015, among which 200 students were selected using census method. This was a descriptive-correlational study. To collect data, Assertion Inventory (Gambrill \& Richie, 1975) and Cognitive-Emotion Regulation Questionnaire (Garnefski et al., 2001) were used. To analyze the obtained data, both descriptive (mean, standard deviation) and inferential statistics (Pearson correlation coefficient and regression analysis) were applied, using SPSS. The results indicated that all subscales of emotional self-regulation were significantly related to assertiveness and self-assertion.
\end{abstract}

\section{Keywords}

Assertiveness, Self-Assertion, Emotional Self-Regulation, Female High School Students

\section{Introduction}

Emotional development is among the variables that play a significant role in the academic progress and achievement (Greenhalgh, 2009). To facilitate the learning process, learners' emotional growth should be taken into consideration to understand the relationship between emotions and learning better. On the other hand, home, with its own rules and procedures, school, with teachers and its educational atmosphere, peers, and the culture governing relations affect students' emotional growth (Morris et al., 2007). Therefore, one of the main factors,

${ }^{*}$ Corresponding author. 
neglected in the educational procedures, with which students are encountered is inability to express emotions and self-assertion. Self-assertion is a critical component of social skills. An individual who is capable of selfassertion, while insisting on his/her reasonable demands and conducting behaviors in their defense, he/she considers others' rights and interests and attempts to avoid violating the rights of others (Gibson, 2003). Generally speaking, self-assertion refers to an individual's ability to express and defend his/her ideas, interests and feelings in a worthy matter and without anxiety (Lizarrage et al., 2003). A person who has self-assertion takes responsibility for his/her own behaviors and choices, has sufficient self-esteem and positive thoughts and attitudes towards himself/herself and others, and his/her behavior is frank and honest with himself/herself and others (Morris et al., 2005). This person can apply communicative methods which enable him/her to maintain self-esteem that lead to happiness and satisfaction (Bolton, 2007).

Self-regulation is the other critical factor which influences students' academic performance and emotional and affective growth. Self-regulation is defined as a mental effort to control internal status, processes and functions to achieve higher goals (Cole, Longman, \& Walker, 2011: p. 1). Lang and Jakowbdki (1978) asserted that assertiveness skills include the ability to defend your rights, express your thoughts, emotions, and beliefs in an appropriate, direct, and honest ways such that others' rights do not violated. The method of interacting with others is an important factor in social interactions. Poor communication can establish unhealthy relations and increase mental pressure. One of the key factors in interpersonal communications is the ability to use assertiveness properly. Poor assertiveness can creates several problems for the individual and others. Accordingly, assertiveness training is a structured method of intervention which is used to improve the effectiveness of social relations and is applied to treat anxiety disorders and phobias in children, adolescents and adults. An assertive person can establish close relationships with others, avoid himself/herself from being abused and express a wide range of needs and positive and negative thoughts without guilt and anxiety or violating others' rights (Aghaei et al., 2003). The main purpose of these assertiveness trainings and programs, in their traditional form, is aiding people to perceive the theoretical concept of determination and apply skills related to it. Through gaining knowledge of various types of behavior, people learn to take responsibility of choosing their own behaviors. This means that if, as an instance, a person, in a special situation, behaves non-assertively or aggressively, he/she does that deliberately and accepts responsibility for his/her selection (Townend, 2007: p. 18). In an assertiveness training, an individual is taught how to form a behavior based on assertiveness and courage. A person learns appropriate methods using assertiveness to express his/her demands through attempting to explore and define a problem, pursuing considered goals (always behaving assertively), repeating the role, reversing the role, and providing gradual and continuous desired behaviors.

Assertive behaviors are convergence to and correlated with positive self-concept, self-esteem, mastery, selfefficacy, and self-confidence and non-assertive behaviors are preventive and avoidant and are highly correlated with fears, phobias, social anxiety and a variety of internal aggression. Several studies have conducted to examine the use of assertiveness training as a treatment method. However, the present study aimed to examine the role of assertiveness and self-assertion in female students' emotional self-regulation considering the subscales of emotional self-regulation.

The current study attempted to indicate that assertiveness and self-assertion play key roles in regulating emotions. To this end, female high school students in Jalagh were selected as the sample. Given what was mentioned earlier, this study sought to answer this question that does assertiveness training affect students' emotional selfregulation and self-assertion?

Ya'ghobi (1998), in a study, indicated that assertiveness training improved social skills through playing the role as a group. Ghafarianzadeh (2000) reported the positive impacts of assertiveness training on academic achievement and social skills of female middle and high school students in district 14 in Tehran. Moreover, Nisi and Shahni Yeylagh (2001), in a study carried out on first grade male high school students in Ahvaz, concluded that assertiveness training increased self-assertion, self-esteem, and mental health and decreased anxiety. Additionally, a study conducted in Shiraz by Rahimi et al. demonstrated that assertiveness training decreased social anxiety and increased social skills including self-assertion. The results of this study showed that school counseling centers play an important role in improving students' social and academic performance and consultants can teach students how to use healthy assertiveness and prevent behavioral disorders and learning problems in this way (Aghaei et al., 2003).

Studies conducted by Deluty (1981) and Kipper (1992), examining the effectiveness of assertiveness training, proved that this training decreased anxiety and improved academic achievement. On the other hand, some stu- 
dies suggested that lack of assertiveness skills in adolescents may lead to aggression in interpersonal relationships. Therefore, since this skill can be learned, after learning, it can be applied in interpersonal relationships. Stangor (2004) indicated that social skills training, particularly assertiveness training, play a key role in controlling anger impulses and aggressive behaviors.

\section{Methods}

This descriptive-correlational study aimed to investigate the role of assertiveness and self-assertion in emotional self-regulation of female students. The statistical population included all second period female high school students in Jalagh, in the academic year 2014-2015, among which 200 students were selected using census method.

To collect data, Assertion Inventory (Gambrill \& Richie, 1975) and Emotion Regulation Questionnaire (Garnefski et al., 2001) were used.

Assertion Inventory: This inventory was developed by Gambrill and Richie (1975) including 40 questions. Each question indicates a situation for which the respondents should express their degree of concern. Degree of mental distress which refers to the amount and intensity of anxiety and discomfort of respondents when faced with that situation, indicating incidence rate related to a behavior, i.e. the possibility of conducting that behavior. Gambrill and Richie (1975) believed that considering its reliability, there is a high correlation between the subscales of this test. Factor reliability of various subscales of this test ranged from 0.39 to 0.70 and its reliability coefficient was 0.81 . The validity of this inventory was examined and confirmed by educational sciences experts, psychologists working at Allameh Tabataba’i University and Isfahan University.

Cognitive-Emotion Regulation Questionnaire: This scale was developed by Garnefski et al. (2001). This scale contains 36 items. Cognitive-emotion regulation questionnaire evaluates nine cognitive strategies including self-blame, acceptance, rumination, positive, reappraisal, planning, positive refocusing, putting into perspective, catastrophizing, blaming others.

Descriptions of the questionnaire:

1) Self-blame: When facing with mishaps, one blames and accuses himself/herself for what has happened.

2) Blaming others: When facing with mishaps, one blames others and considers others the main reason for what has happened.

3) Rumination: One expresses and perceives the outbreak of a condition more severe and terrifying than the reality of that incident.

4) Catastrophizing: One expresses and perceives a condition more severe and terrifying than the reality of that incident.

5) Acceptance: When dealing with adverse conditions, one makes himself/herself accept the condition. As Garnefski et al. (2006) asserted, cognitive emotion regulation strategies are actions that indicate how to cope with stressful situations and mishaps.

6) Positive refocusing and planning: When confronting with mishaps, one focuses on positive experiences and apply planning to decrease the negative complications of that stressful event.

7) Positive reappraisal and putting into perspective: When facing with adverse conditions, one uses valuable experiences which he/she gained from dealing with the situation and emphasizes the constructive nature of the condition. Moreover, to decrease the importance of the adverse condition, one attempts to extend and develop individual perspectives.

Alpha coefficient of the subscales of this questionnaire was assessed by Garnefski et al. (2002) which ranged from 0.71 to 0.81 .

To analyze the obtained data, both descriptive (mean, standard deviation) and inferential statistics (Pearson correlation coefficient and regression analysis) were applied using SPSS.

\subsection{Descriptive Data}

According to Table 1, mean and standard deviation related to self-blame are respectively 2.03 and 0.62 , mean and standard deviation of blaming others are 2.35 and 0.64 , mean and standard deviation of rumination are respectively 1.98 and 0.37 , mean and standard deviation of positive refocusing are 2.41 and 0.46 and mean and standard deviation of refocusing on planning are 2.71 and 0.64 .

Moreover, mean and standard deviation of positive reappraisal are 2.11 and 0.58 , mean and standard deviation of putting into perspective are 2.04 and 0.71 and mean and standard deviation of catastrophizing are 2.29 and 
0.87

Based on Table 2, mean and standard deviation of students' assertiveness and self-assertion are respectively 113.41 and 34.00 .

\subsection{Inferential Statistics}

First Hypothesis: Assertiveness and self-assertion are significantly correlated with emotional self-regulation in female high school students.

To examine this hypothesis, Pearson correlation coefficient was used.

As Table 3 demonstrated, self-blame has a significant negative correlation with assertiveness and self-assertion $(r=-0.40, p<0.01)$. Moreover, assertiveness and self-assertion are positively and significantly correlated with blaming others $(r=0.285, p<0.01)$, rumination $(r=0.177, p<0.05)$, positive refocusing $(r=0.34, p<0.01)$, refocusing on planning $(r=0.232, p<0.05)$, positive reappraisal $(r=0.38, p<0.01)$, and catastrophizing $(r=$

Table 1. Descriptive statistics related to subscales of cognitive emotion regulation.

\begin{tabular}{cccccccc}
\hline Predictive variables & N & Mean & SD & Min & Max \\
\hline Self-blame & 200 & 2.03 & 0.62 & 0.58 & 3.50 \\
Blaming others & 200 & 2.35 & 0.64 & 0.63 & 3.42 \\
Rumination & 200 & 1.98 & 0.37 & 1.00 & 3.17 \\
Emotion regulation & Positive refocusing & 200 & 2.41 & 0.46 & 1.27 & 3.58 \\
& Refocusing on planning & 200 & 2.71 & 0.64 & 1.00 & 3.83 \\
& Positive reappraisal & 200 & 2.11 & 0.58 & 1.61 & 4.25 \\
& Putting into perspective & 200 & 2.04 & 0.71 & 1.00 & 4.17 \\
& Catastrophizing & 200 & 2.29 & 0.87 & 1.00 & 4.05 \\
& Total emotion regulation & 200 & 2.19 & 0.42 & 1.52 & 4.20
\end{tabular}

Table 2. Mean and standard deviation of scores related to assertiveness and self-assertion as the criterion variable of the current study.

\begin{tabular}{cccccc}
\hline Criterion variable & N & Mean & SD & SK \\
\hline Assertiveness and self-assertion & 200 & 113.41 & 34.00 & -0.04 \\
\hline
\end{tabular}

Table 3. Pearson correlation coefficients of emotional self-regulation with assertiveness and self-regulation.

\begin{tabular}{cccc}
\hline \multirow{2}{*}{ Variables } & \multicolumn{2}{c}{ Assertiveness and self-regulation } \\
& Correlation coefficient & Sig & $\mathrm{N}$ \\
\cline { 2 - 4 } Self-blame & $-0.40^{* *}$ & 0.0005 & 200 \\
Blaming others & $0.285^{* *}$ & 0.0005 & 200 \\
Rumination & $0.177^{* *}$ & 0.012 & 200 \\
Positive refocusing & 0.340 & 0.0005 & 200 \\
Refocusing on planning & 0.232 & 0.001 & 200 \\
Positive reappraisal & 0.38 & 0.0005 & 200 \\
Putting into perspective & -0.430 & 0.0005 & 200 \\
Catastrophizing & 0.381 & 0.0005 & \\
\hline
\end{tabular}

$P<0.01$. 
0.381, $p<0.01$ ). Additionally, there is a significant negative correlation between putting into perspective and assertiveness and self-assertion $(r=-0.43, p<0.01)$.

Second Hypothesis: Which subscale of emotional self-regulation can predict assertiveness and self-assertion? Criterion variable: assertiveness and self-assertion in female students

The results of regression analysis carried out to predict assertiveness and self-assertion in female students, demonstrated in Table 4, indicate that in the first step, a subscale of emotional self-regulation, i.e. positive refocusing, entered the regression equation and reversely explained $18.4 \%$ of the variance of assertiveness and self-regulation. Afterwards, another subscale of emotional self-regulation, i.e. positive reappraisal, entered the equation and explained $7.4 \%$ of the variance of assertiveness and self-regulation. In the third step, the subscale of putting into the perspective entered the equation and explained $4.9 \%$ of the variance of assertiveness and selfassertion. Therefore, the proposed model can explain $31.0 \%$ of the variance of assertiveness and self-assertion in female students.

Considering non-standard coefficients, the final regression equation can be determined in three steps to predict the score of assertiveness and self-assertion as follows:

Exceptional children teachers' job satisfaction $=170.03+$ (positive refocusing $\left.-15.05^{*}\right)+($ putting into perspective $\left.-16.75^{*}\right)+$ (positive reappraisal 12.69*).

\section{Discussion}

First Hypothesis: Assertiveness and self-assertion are significantly correlated with emotional self-regulation in female high school students.

The results related to the first hypothesis using the correlation test indicated that the subscales of self-regulation were significantly correlated with assertiveness and self-assertion. The correlations of the subscales of emotional self-regulation with assertiveness and self-assertion were significant $(p<0.01)$.

Using stepwise regression analysis, the priorities of variables predicting assertiveness and self-assertion in female students were examined. As demonstrated in Table 4, the results showed that the subscale of positive reappraisal was the best predicator of assertiveness and self-assertion and also had the highest correlation coefficient. Considering the main objective of the current study, examining the relationship of assertiveness and selfassertion with emotional self-regulation in female students, it can be concluded that despite the fact that all subscales of emotional self-regulation were correlated with assertiveness and self-regulation, people who apply adaptive coping strategies in the face of stress and negative emotions have better levels of physical health.

These results are in line with the results of Ghafarianzadeh (2000) and Ya'ghobi (2008). The results of Stangor (2004) indicated that social skills training, particularly assertiveness training, play a key role in controlling anger impulses and aggressive behaviors.

Second Hypothesis: Which subscale of emotional self-regulation can predict assertiveness and self-assertion? To examine this hypothesis stepwise multiple linear regression was used. In this analysis, assertiveness and self-assertion were considered as the criterion variable and nine subscales of self-regulation (self-blame, acceptance, rumination, positive, reappraisal, planning, positive refocusing, putting into perspective, catastrophizing, blaming others) were considered as predictive variables. The results demonstrated that three subscales of emotional self-regulation, i.e. positive refocusing, positive reappraisal, and putting into perspective, entered into the regression equation and others were eliminated. Examining the regression coefficients indicated that these three subscales could predict assertiveness and self-assertion significantly.

Table 4. Results of stepwise regression analysis conducted to predict assertiveness and self-assertion based on the subscales of emotional self-regulation in female students.

\begin{tabular}{|c|c|c|c|c|c|c|c|c|c|}
\hline \multirow{2}{*}{ Pattern } & \multirow{2}{*}{$\mathrm{R}$} & \multirow{2}{*}{$\mathrm{R}^{2}$} & \multirow{2}{*}{$\begin{array}{c}\text { Change statistics } \\
\mathrm{R}^{2} \text {-change }\end{array}$} & \multicolumn{2}{|c|}{ Non-standard coefficients } & \multicolumn{2}{|c|}{ Standard coefficients } & \multirow{2}{*}{$\mathrm{t}$} & \multirow{2}{*}{ Sig. } \\
\hline & & & & Sig. F & $\mathrm{B}$ & Sd. E & Beta & & \\
\hline Positive refocusing & 0.43 & 0.184 & 0.1 & 0.000 & -15.05 & 4.28 & -0.326 & -3.52 & 0.001 \\
\hline Positive reappraisal & 0.51 & 0.26 & 0.074 & 0.003 & 12.69 & 4.45 & 0.266 & -2.85 & 0.005 \\
\hline Putting into perspective & 0.55 & 0.31 & 0.049 & 0.011 & -16.75 & 6.49 & -0.223 & -2.58 & 0.011 \\
\hline Constant & & & & & 170.03 & 26.61 & & 6.39 & 0.0005 \\
\hline
\end{tabular}




\section{Conclusion}

Since, in the current study, three subscales of emotional self-regulation were the best predicators of assertiveness and self-assertion. Therefore, it can be concluded that effective communication skills training can aid decreasing the use of rumination; however, this training is not effective in reducing blaming others. In general, cognitivebehavioral training program can increase the use of problem-focused coping responses and some cognitive strategies focused on planning, refocusing, positive reappraisal in regulating emotions. Moreover, cognitivebehavioral training can decrease the sustainable use of emotion-focused coping responses and some cognitive strategies including self-blame, rumination, catastrophizing in regulating emotions.

\section{Limitations}

1) Since only second period female high school students in Jalagh were considered as the statistical population of the current study, when generalizing the obtained results, caution should be taken.

2) Considering female high school students as the sample of this study can be mentioned as a limitation.

3) Lack of access to research and studies fully related to the current study was another limitation.

\section{Recommendations}

1) Holding training sessions for school teachers and instructors and inviting experts and university professors to explain the significance of this issue and present methods in seminars, presentations, and conferences aiding teachers to become familiar with self-assertion.

2) Encouraging teachers to use modern teaching methods with an emphasis on students' active participation in the classroom.

3) Holding training session for teachers to identify students who have low self-assertion and planning for overcoming this low self-assertion in the classroom and at school.

4) Paying attention to educational and extra-curricular activities at school and giving responsibilities to students who have some difficulty regarding the issue.

It is recommended that similar research be conducted on a broader level to obtain more reliable results.

\section{References}

Aghaei, A., Malekpour, M., \& Ajami, Gh. R. (2003). Effect of Assertiveness Training on Self-Assertive Behavior of Male and female High School Students in Naien, Isfahan. Knowledge and Research in Applied Psychology, 5, 17-28.

Bolton, R. (2007). Psychology of Human Relationships (People Skills). Translated by: Sohrabi, H.R., \& Hayat Roshanaeei, A. Tehran: Roshd Pubilcation.

Cole, J., Logan, T. K., \& Walker, R. (2011). Social Exclusion, Personal Control, Self-Regulation, and Stress among Substance Abuse Treatment Clients. Drug and Alcohol Dependence, 113, 13-20.

http://dx.doi.org/10.1016/j.drugalcdep.2010.06.018

Deluty, R. H. (1981). Assertiveness in Children: Some Research Considerations. Journal of Clinical Child Psychology, 10, 149-155. http://dx.doi.org/10.1080/15374418109533037

Gambrill, E. D., \& Richie, C. A. (1975). An Assertion Inventory for Use in Assessment and Research. Behavior Therapy, 6, 550-561. http://dx.doi.org/10.1016/S0005-7894(75)80013-X

Garnefski, N., \& Kraaij, V. (2006) Cognitive Emotion Regulation Questionnaire-Development of a Short 18-Item Version (CERQ-Short). Personality and Individual Differences, 41, 1045-1053. http://dx.doi.org/10.1016/j.paid.2006.04.010

Garnefski, N., Kraaij, V., \& Spinhoven, P. (2002). Manual for the Use of the Cognitive Emotion Regulation Questionnaire. The Netherlands: DATEC, Leiderdorp.

Garnefski, N., Kraaij, V., \& Spinhoven, P. (2001). Negative Life Events, Cognitive Emotion Regulation, and Emotional Problems. Personality and Individual Differences, 30, 1311-1327. http://dx.doi.org/10.1016/S0191-8869(00)00113-6

Ghafarianzadeh, S. (2000). The Impact of Assertiveness Group Counseling on Academic Achievement and Social Skills of Middle and High School Female Students in District 14, Tehran. MA Thesis, Tehran: Tehran University.

Gibson, D. E. (2003). Developing the Professional Self-Concept: Role Model Construal's at Early, Middle and Late Career Stages. Organization Science, 24, 591-610. http://dx.doi.org/10.1287/orsc.14.5.591.16767

Greenhalgh, P. (2009). Emotional Growth and Learning. New York: Routledge.

Kipper, D. A. (1992). The Effect of Two Kinds of Role Playing on Self-Evaluation of Improved Assertiveness. Journal of 
Clinical Psychology, 48, 246-250.

http://dx.doi.org/10.1002/1097-4679(199203)48:2<246::AID-JCLP2270480217>3.0.CO;2-B

Lang, A. J., \& Jakowbdki, P. (1978). Responsible Assertive Behavior (4th ed.). Washington DC: Research Press.

Lizarrage, M. L., Ugarte, M. D., Cardelle-Elawar, M., \& Iriarte, M. D. (2003). Enhancement of Self-Regulation, Assertiveness, and Empathy. Learning and Instruction, 13, 423-439. http://dx.doi.org/10.1016/S0959-4752(02)00026-9

Morris, A. S., Robinson, L., \& Eisenberg, N. (2005). Applying a Multi Method Perspective to the Study of Developmental Psychology. In M. Eid, \& E. Diener (Eds.), Handbook of Multi-Method Measurement in Psychology (pp. 371-384). Washington DC: APA Books.

Morris, A. S., Robinson, L. R., Halliburton, A. L., Aucoin, K. J., Keyes, A. W., \& Terranova, A. (2007). The Role of Emotion Regulation and Reactivity in Children School Adjustment. Journal of Applied Developmental Psychology, 30.

Nisi, A. A., \& Shahni Yeylagh, M. (2001). The Effect of Self-Assertion Training on Self-Assertion, Self-Esteem, Social Anxiety, and Mental Health of Anxious Male High School Students in Ahvaz. Journal of Educational Sciences and Psychology, 3, 11-30.

Stangor, C. (2004). Social Groups in Action and Interaction. New York: Psychology Press.

Townend, A. (2007). Assertiveness and Diversity. New York: Palgrave Macmillan. http://dx.doi.org/10.1057/9780230582019 